\title{
Multiwire Shielded Cable Parameter Computation
}

\author{
Mamadou Kane, Ahmad Ahmad, Philippe Auriol \\ CEGELY - C.N.R.S. URA 829 \\ Ecole Centrale de Lyon - 36, avenue Guy de Collongue - 69131 Ecully Cedex - France
}

\begin{abstract}
A procedure is presented for the efficient computation of multiwire shielded cable parameters. In order to reduce the calculation time. a special technique is used to calculate the magnetic field using Bessel functions. The skin and proximity effects are taken into account in a frequency range where displacement currents can be neglected.

The results obtained with the present model were compared successfully with those obtained by the FEM.
\end{abstract}

\section{INTRODUCTION}

In many applications of circular conductors, high accuracy is required for the computation of flux densities and cable parameters. It is well known that the skin and the proximity effects cause nonuniform current distributions and increased [1]-[7] power losses in multiwire shielded cables. Approximate analytical methods are often not advised. Numerical methods are used for improved accuracy. Expensive time is needed to compute all the parameters by solving Maxwell's equations with numerical methods for applications in a wide range of frequencies (from $0 \mathrm{~Hz}$ to 10 $\mathrm{MHz}$ ). The existing models suppose an infinite external radius [8], [9] and cannot take account of proximity effects in inner conductors [8], [9]. Even if proximity effects are introduced in parameter calculations, a symmetrical configuration of inner conductors with equal radii is imposed [10]. A new approach has been developed with the aim of determining the values of multiwire shielded cable parameters using a special technique. The proposed method takes into account the finite thickness of the shield, skin and the most important proximity effects in all conductors and the shield. The generated formulae could be used in a symmetrical or non-symmetrical configuration of inner conductors and, their radii could be different. The obtained results are given in a matrix form. In order to verify the validity of the proposed method, the results obtained were compared with those from the Finite Element Method.

\section{FORMULATION}

Conductors are assumed parallel to one another and their lengths infinite (no edge effects). The displacement current is neglected in the conductor medium. Currents and fields are sinusoidal with an angular frequency $\omega$. The inner conductor $\mathbf{i}$ of the system and the shield $g$ have permeabilities $\mu_{i}=\mu_{0} \mu_{r i}$ and $\mu_{\mathrm{g}}=\mu_{0} \mu_{\mathrm{rg}}$ and conductivities $\sigma_{\mathrm{i}}, \sigma_{\mathrm{g}}$ that are assumed to be linear, homogenous, and isotropic. A system of cylindrical co-ordinates is used. The system consists of $\mathrm{P}$ conductors

Manuscript received July 5, 1994 located in the hollow of the shield and carrying currents Ii which return via the shield when the cable is in free space as shown in Fig. 1.

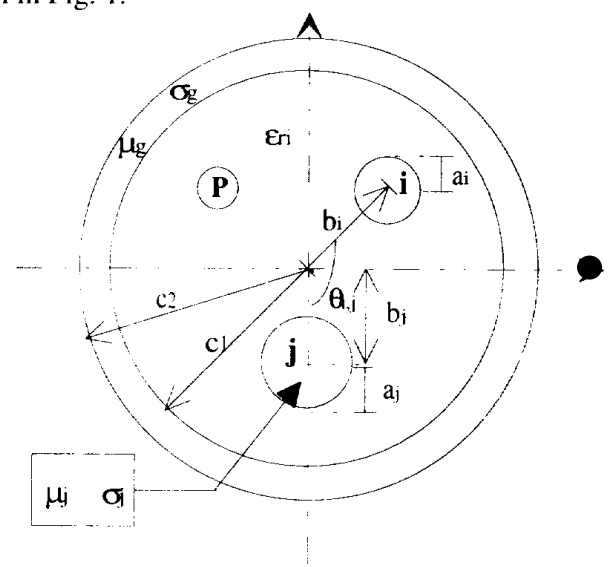

Fig. 1. Multiwire shielded cable section

A formulation based on magnetic vector potential $\mathbf{A}$ is used to solve this problem [11]. All current densities and magnetic vector potentials are assumed to be in the $\mathrm{z}$ direction. In this configuration. let the shield be the reference conductor. In order to determine the per unit length self and mutual impedances of the system, we use the superposition theorem, taking into account the magnetic vector potential contributions of the conductors and the shield.

For the i-th self impedance calculation Faraday's law with flux linkage techniques is applied to the $\mathrm{i}$-th conductor and the shield. For the ij-th mutual impedance, the same principle is applied by considering conductors $i$ and $j$ with the shield as reference.

\section{SELF IMPEDANCE OF CONDUCTOR I AND THE SHIELD}

In this part, it is first considered that conductor $\mathrm{i}$ is a filamentary one. An application of Faraday's law with flux linkage technique is then applied to the circuit consisting of the conductor $i$ and the shield as shown in Fig. 2 .The basic equations are expressed as follows :

$-\frac{\partial V_{i}}{\partial z}=\left(R_{g}+j L_{g} \omega\right) \mathbf{I} i=\frac{d \Phi_{i}}{d t}+\mathbf{E z}\left(c_{1}, \theta\right)$

where,

$\frac{\mathrm{d} \Phi_{\mathrm{i}}}{\mathrm{dt}}=\mathrm{j} \omega \oint_{l} \operatorname{Aint}(\rho, \theta) \mathrm{d} l=\mathrm{j} \omega\left[\operatorname{Aint}\left(\mathrm{c}_{1}, \theta\right)-\operatorname{Aint}\left(\mathrm{b}_{\mathrm{j}}, 0\right)\right]$

$\mathbf{E z}\left(\mathrm{c}_{1}, \theta\right)=\left(\frac{1}{\sigma_{\mathrm{g}}}\right) \mathbf{J}_{\mathrm{g}}\left(\mathrm{c}_{1}, \boldsymbol{\theta}\right)$ 


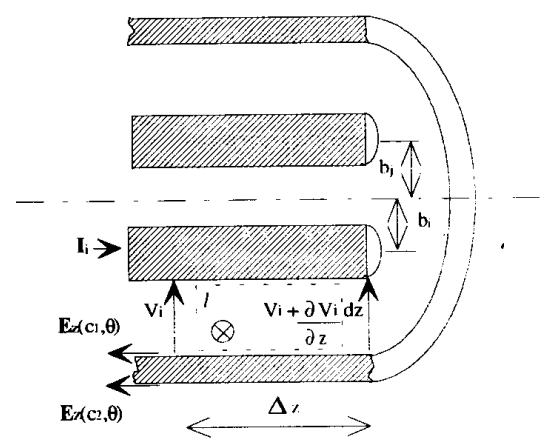

Fig. 2. Faraday's law application to the conductor $i$ and the shield for self impedance calculation

In these expressions, $\operatorname{Aint}(\rho, \theta)$ characterizes the magnetic vector potential inside the hollow of the shield while $\operatorname{Ez}\left(c_{1}, \theta\right)$ represents the axial electric field at the inner surface of the shield. Hence, we can derive the formula for the impedance $\left(\mathrm{R}_{\mathrm{g}}+\mathrm{jL} \mathrm{g} \omega\right)$ of the considered circuit with the previous equations $(1,2,3)$ as follows:

$\left(R_{g}+j L_{g} \omega\right) I i=\left(\frac{1}{\sigma_{g}}\right)\left[A_{0} I_{0}\left(c_{1} \sqrt{j \omega \mu_{g} \sigma_{g}}\right)+B_{0} K_{0}\left(c_{1} \sqrt{j \omega \mu_{g} \sigma_{g}}\right)\right]$

$+\left(\frac{1}{\sigma_{g}}\right) \sum_{n=1}^{\infty}\left(\frac{b_{i}}{c_{l}}\right) n\left[A_{n} I_{n}\left(c_{1} \sqrt{j \omega \mu_{g} \sigma_{g}}\right)+B_{n} K_{n}\left(c_{1} \sqrt{j \omega \mu_{g} \sigma_{g}}\right)\right]$

$+j \omega \frac{\mu_{0} \mathbf{I} i}{2 \pi} \operatorname{Ln}\left[\frac{\left(c_{1}^{2}-b_{i}^{2}\right)}{c_{1} a_{i}}\right]$

In this formula, the first term of the right hand side is due to the skin effect development in the shield material while the second is due to the proximity effects and the third characterizes the external inductance between the conductor $i$ and the shield. Constants $A_{0} B_{0} A_{n} B_{n}$ are obtained by boundary conditions applied at the shield's surfaces.

$$
\begin{aligned}
& A_{n}=\frac{\text { Ii } \sqrt{j \omega \mu_{g} \sigma_{g}}}{2 \pi \Delta}(P n+Q n)\left[\frac{\mu_{r g} n}{c_{2} \sqrt{j \omega \mu_{g} \sigma_{g}}} K_{n}\left(c_{2} \sqrt{j \omega \mu_{g} \sigma_{g}}\right)\right. \\
& \left.+K_{n}^{\prime}\left(c_{2} \sqrt{j \omega \mu_{g} \sigma_{g}}\right)\right] \\
& B_{n}=-\frac{I i \sqrt{j \omega \mu_{g} \sigma_{g}}}{2 \pi \Delta}(P n+Q n)\left[\frac{\mu_{r_{g}} n}{c_{2} \sqrt{j \omega \mu_{g} \sigma_{g}}} I_{n}\left(c_{2} \sqrt{j \omega \mu_{g} \sigma_{g}}\right)\right. \\
& \left.+I_{n}^{\prime}\left(c_{2} \sqrt{j \omega \mu_{g} \sigma_{g}}\right)\right]
\end{aligned}
$$

In these expressions, $\mathbf{I}$ : characterizes the current carrying by the conductor $i$ which returns through the shield, while $I_{n}$ and $K_{n}$ denote respectively modified Bessel functions of the first and second kind of order $n$.

-for $\mathrm{n}=0$ we have : $\mathrm{P} 0=\frac{1}{c_{1}}$ and, $\mathrm{Q}_{0}=0$

-and for $(n>0)$, we have : $P_{n}=\frac{1}{c_{1}}\left(\frac{b_{i}}{c_{1}}\right)^{n}$ and, $Q n=\frac{1}{c_{1}}\left(\frac{b_{i}}{c_{1}}\right)^{n}$

We also give the following expression of $\Delta$.

$$
\begin{aligned}
& \Delta=\left[\frac{\mu_{r_{g}} n}{c_{1} \sqrt{j \omega \mu_{g} \sigma_{g}}} I_{n}\left(c_{1} \sqrt{j \omega \mu_{g} \sigma_{g}}\right)-I_{n}^{\prime}\left(c_{1} \sqrt{j \omega \mu_{g} \sigma_{g}}\right)\right] . \\
& .\left[\frac{\mu_{r_{g}} n}{c_{2} \sqrt{j \omega \mu_{g} \sigma_{g}}} K_{n}\left(c_{2} \sqrt{j \omega \mu_{g} \sigma_{g}}\right)+K_{n}^{\prime}\left(c_{2} \sqrt{j \omega \mu_{g} \sigma_{g}}\right)\right]
\end{aligned}
$$

$$
\begin{aligned}
& -\left[\frac{\mu_{r_{g}} n}{c_{2} \sqrt{j \omega \mu_{g} \sigma_{g}}} I_{n}\left(c_{2} \sqrt{j \omega \mu_{g} \sigma_{g}}\right)+I_{n}^{\prime}\left(c_{2} \sqrt{j \omega \mu_{g} \sigma_{g}}\right)\right] \\
& -\left[\frac{\mu_{r_{g}} n}{c_{1} \sqrt{j \omega \mu_{g} \sigma_{g}}} K_{n}\left(c_{1} \sqrt{j \omega \mu_{g} \sigma_{g}}\right)-K_{n}^{\prime}\left(c_{1} \sqrt{j \omega \mu_{g} \sigma_{g}}\right)\right]
\end{aligned}
$$

It is important to note that the surface impedance of the shield in the case of excentric conductor located in the hollow of the shield, noted $\left(R_{s}+j L_{s} \omega\right)$ is given by:

$$
\left(R_{s}+j L_{s} \omega\right)=\left(R_{g}+j L_{g} \omega\right)-j \omega \frac{\mu_{0}}{2 \pi} \operatorname{Ln}\left[\frac{\left(c_{1}{ }^{2}-b_{i}{ }^{2}\right)}{c_{1} a_{i}}\right]
$$

and in the case of $b_{i}=0$ this impedance becomes the skin effect surface impedance given by Shelkunhoff [12].

We also deduce from formula (4) the self inductance expression in a losseless case $\left(\mathrm{L}_{\mathrm{ii}}\right)$ and the capacitance $\left(\mathrm{C}_{\mathrm{ii}}\right)$ between conductor $i$ and the shield as follows :

$$
\mathrm{L}_{\mathrm{ii}}=\frac{\mu_{0}}{2 \pi} \operatorname{Ln}\left[\frac{\left(\mathrm{c}_{1}^{2}-\mathrm{b}_{\mathrm{i}}^{2}\right)}{\mathrm{c}_{1} \mathrm{a}_{\mathrm{i}}}\right] \text { and, } \mathrm{L}_{\mathrm{ii}} \cdot \mathrm{C}_{\mathrm{ii}}=\mu_{0} \varepsilon_{0} \varepsilon_{\mathrm{ri}}
$$

$\left(\varepsilon_{\mathrm{ri}}\right.$ is the relative permeability of the dielectric inside the shield).

In the formula (4) , it was supposed that the conductor $i$ was a current filament. The calculated impedance $\left(R_{g}+j L_{g} \omega\right)$ is added to the impedance ( $z_{i i i}^{\prime}$ ) of the conductor $i$ with its own radius. Hence, the sum of these two impedances characterizes the total impedance $\left(\mathrm{Z}_{\mathrm{i}, \mathrm{i}} \mathrm{Tot}\right)$ of the considered circuit.

The impedance of the conductor $i$ consists therefore of the sum of the skin effect impedance of the conductor $i$ and the impedance due to eddy currents development in all the other (P-1) near conductors [13]. This gives:

$$
z_{i i i}^{\prime}=\left(\frac{1}{\sigma_{i}}\right)\left[\frac{\sqrt{j \omega \mu_{i} \sigma_{i}}}{2 \pi a i} \frac{I_{0}\left(a i \sqrt{j \omega \mu_{i} \sigma_{i}}\right)}{I_{1}\left(a i \sqrt{j \omega \mu_{i} \sigma_{i}}\right)}\right]+\sum_{k=1, k \neq i}^{P} z_{i k i}^{\prime}
$$

with,

$$
\begin{aligned}
& z_{i k i}^{\prime}=\left(\frac{1}{\sigma_{k}}\right)_{n=1}^{\infty} \frac{\mu_{0} j \omega \sigma_{k} a k^{n-1}}{\pi}\left(\frac{a k}{b i k}\right)^{n}\left[\left(\frac{1}{b i k}\right)^{n}\right] I_{n}\left(a k \sqrt{j \omega \mu_{k} \sigma_{k}}\right) \\
& \cdot\left[\frac{1}{\left(\frac{n}{a k}\right) I_{n}\left(a k \sqrt{j \omega \mu_{k} \sigma_{k}}\right)+\left(\frac{\sqrt{j \omega \mu_{k} \sigma_{k}}}{\mu_{r k}} I_{n}\left(a k \sqrt{j \omega \mu_{k} \sigma_{k}}\right)\right.}\right]
\end{aligned}
$$

It is important to note that in this expression. bik is the interaxial distance between conductor $\mathrm{i}$ and conductor $\mathrm{k}$, while ak, $\mu_{\mathrm{k}}$ and $\sigma_{\mathrm{k}}$, denote the radii, the relative permeability and the conductivity of conductor $k$, respectively. Hence, the total impedance is given by the following expression :

$$
\begin{aligned}
& \mathrm{Z}_{\mathrm{i}, \mathrm{i}} \text { Tot }=\left(\mathrm{R}_{\mathrm{i}, \mathrm{i}} \text { Tot }+\mathrm{jL}_{\mathrm{i}, \mathrm{i}} \text { Tot } \omega\right)=\left(\mathrm{R}_{\mathrm{g}}+\mathrm{jL}_{\mathrm{g}} \omega\right)+\mathrm{z}_{\mathrm{iii}}^{\prime} \\
& =\left(\frac{1}{I_{i} \sigma_{g}}\right)\left[A_{0} I_{0}\left(c_{1} \sqrt{j \omega \mu_{g} \sigma_{g}}\right)+B_{0} K_{0}\left(c_{1} \sqrt{j \omega \mu_{g} \sigma_{g}}\right)\right] \\
& +\left(\frac{1}{I i \sigma_{g}}\right) \sum_{n=1}^{\infty}\left(\frac{b_{i}}{c_{1}}\right)^{n}\left[A_{n} I_{n}\left(c_{1} \sqrt{j \omega \mu_{g} \sigma_{g}}\right)+B_{n} K_{n}\left(c_{1} \sqrt{j \omega \mu_{g} \sigma_{g}}\right)\right] \\
& +j \omega \frac{\mu_{0}}{2 \pi} \operatorname{Ln}\left[\frac{\left(c_{1}^{2}-b_{i}^{2}\right)}{c_{1} a_{i}}\right]+ \\
& +\left(\frac{1}{\sigma_{i}}\right)\left[\frac{\sqrt{j \omega \mu_{i} \sigma_{i}}}{2 \pi a i} \frac{I_{0}\left(a i \sqrt{j \omega \mu_{i} \sigma_{j}}\right)}{I_{1}\left(a i \sqrt{j \omega \mu_{i} \sigma_{i}}\right)}\right]+\sum_{k=1, k \neq i}^{P} z_{i k i}^{\prime}
\end{aligned}
$$




\section{MUTUAL IMPEDANCE OF CONDUCTOR I AND J}

For the mutual calculation, we first consider conductors $\mathrm{i}$ and $j$ as current filaments. With this configuration, we inject a current Ii through the filament $i$ and apply Faraday's law to conductor $\mathrm{j}$ and the shield which is considered as the return conductor (Fig. 3). Secondly, we take into account eddy current [13] development due to conductor $i$ in conductor $j$.

The application of Faraday's law along the dashed line permit to establish the following equations.

$$
-\frac{\partial V \mathrm{j}, \mathrm{i}}{\partial z}=\left(\mathrm{R}_{\mathrm{j}, \mathrm{i}}+\mathrm{j} \mathrm{L}_{\mathrm{j}, \mathrm{i}} \omega\right) \mathbf{I} \mathrm{i}=\frac{\mathrm{d} \Phi_{\mathrm{ji}}}{\mathrm{dt}}+\mathbf{E} z\left(\mathrm{c}_{1}, \theta\right)
$$

$$
\text { with, }
$$$$
\frac{\mathrm{d} \Phi_{\mathrm{j}, \mathrm{i}}}{\mathrm{dt}}=\mathrm{j} \omega \oint_{l} \operatorname{Aint}(\rho, \theta) \mathrm{d} l=\mathrm{j} \omega\left[\operatorname{Aint}\left(c_{1}, \theta\right)-\operatorname{Aint}\left(\mathrm{b}_{\mathrm{j}}, \theta_{\mathrm{i}, \mathrm{j}}\right)\right]
$$

The resolution of the previous equations gives the mutual impedance formula $\left(R_{j, i}+j L_{j, i} \omega\right)$ in the case where conductors $i$ and $j$ are filamentary.

$\left(\mathrm{R}_{\mathrm{j}, \mathrm{i}}+\mathrm{j} \mathrm{L}_{\mathrm{j}, \mathrm{i}} \omega\right) \mathbf{I}=\left(\frac{1}{\sigma_{\mathrm{g}}}\right)\left[\mathrm{A}_{0} \mathrm{I}_{0}\left(\mathrm{c}_{1} \sqrt{j \omega \mu_{\mathrm{g}} \sigma_{\mathrm{g}}}\right)+\mathrm{B}_{0} \mathrm{~K}_{0}\left(c_{1} \sqrt{j \omega \mu_{\mathrm{g}} \sigma_{\mathrm{g}}}\right)\right]+$ $\left(\frac{1}{\sigma_{g}}\right) \sum_{n=1}^{\infty}\left(\frac{b_{j}}{c_{1}}\right)^{n}\left[A_{n} I_{n}\left(c_{1} \sqrt{j \omega \mu_{g} \sigma_{g}}\right)+B_{n} K_{n}\left(c, \sqrt{j \omega \mu_{g} \sigma_{g}}\right)\right] \cdot \operatorname{Cos}\left(n \theta_{i, j}\right)$ $+j \omega \frac{\mu_{0} I_{i}}{4 \pi} \operatorname{Ln}\left[\frac{c_{1}{ }^{4}+\left(b_{i} b_{j}\right)^{2}-2\left(b_{i} b_{j}\right) c_{1}{ }^{2} \operatorname{Cos}\left(\theta_{i j}\right)}{c_{1}{ }^{2}\left[b_{i}{ }^{2}+b_{j}{ }^{2}-2 b_{i} b_{j} \operatorname{Cos}\left(\theta_{i, j}\right)\right]}\right]$

With this expression. we can derive the classical mutual inductance $\left(\mathrm{L}_{\mathrm{ij}}\right)$ in the case of losseless conductors and the potential coefficient $\left(\mathrm{P}_{\mathrm{ji}}\right)$.

$L_{j i}=\frac{\mu_{0}}{4 \pi} \operatorname{Ln}\left[\frac{c_{1}{ }^{4}+\left(b_{i} b_{j}\right)^{2}-2\left(b_{j} b_{j}\right) c_{1}{ }^{2} \operatorname{Cos}\left(\theta_{i j}\right)}{c_{1}{ }^{2}\left[b_{i}{ }^{2}+b_{j}{ }^{2}-2 b_{i} b_{j} \operatorname{Cos}\left(\theta_{i, j}\right)\right]}\right]$

$P_{\mathrm{ji}}=\frac{L_{\mathrm{ji}}}{\mu_{0} \varepsilon_{0} \varepsilon_{\mathrm{ri}}}$

We must add to the preceding impedance $\left(R_{j, i}+j L_{j, i} \omega\right)$, the impedance ( $Z$ ind,,$j$ ) due to eddy currents of conductor $i$ in conductor $\mathrm{j}[13]$.

$$
\begin{aligned}
& \text { Zind } \left., j=\left(\frac{1}{\sigma_{j}}\right) \sum_{n=1}^{\infty} \frac{\mu_{0} j \omega \sigma_{j} a_{j}^{n-1}}{\pi} I_{n}\left(a_{j} \sqrt{j \omega \mu_{j} \sigma_{j}}\right)\left(\frac{a_{j}}{b_{i j}}\right)^{n} \cdot\left[\frac{1}{b_{i j}}\right)^{n}\right] \\
& \cdot\left[\frac{1}{\left(\frac{n}{a_{j}}\right) I_{n}\left(a_{j} \sqrt{j \omega \mu_{j} \sigma_{j}}\right)+\left(\frac{\sqrt{j \omega \mu_{j} \sigma_{i}}}{\mu_{r j}}\right) I_{n}\left(a_{j} \sqrt{j \omega \mu_{j} \sigma_{j}}\right)}\right]
\end{aligned}
$$

The sum of the two impedances gives the total mutual impedance $\left(\mathrm{Z}_{\mathrm{i}, \mathrm{i}}\right.$ Tot $)$ of conductors $\mathrm{i}$ and $\mathrm{j}$ with the shield as reference conductor.

$Z_{\mathrm{j}, \mathrm{i}} \mathrm{Tot}=\left(\mathrm{R}_{\mathrm{j}, \mathrm{i}} \mathrm{Tot}+\mathrm{j} \mathrm{L}_{\mathrm{j}, \mathrm{i}}\right.$ Tot $\left.\omega\right)=\left(\mathrm{R}_{\mathrm{j}, \mathrm{i}}+\mathrm{j} \mathrm{L}_{\mathrm{j}, \mathrm{i}}(\omega)+\mathrm{Zind}, \mathrm{j}_{\mathrm{i}}\right.$

Finally, to determine $Z_{i, j}$ Tot we impose $(\mathbf{I} i=0, \mathbf{I} \neq \neq 0)$ and conduct the calculations as we made for $\mathrm{Z}_{\mathrm{i}, \mathrm{i}}$ Tor

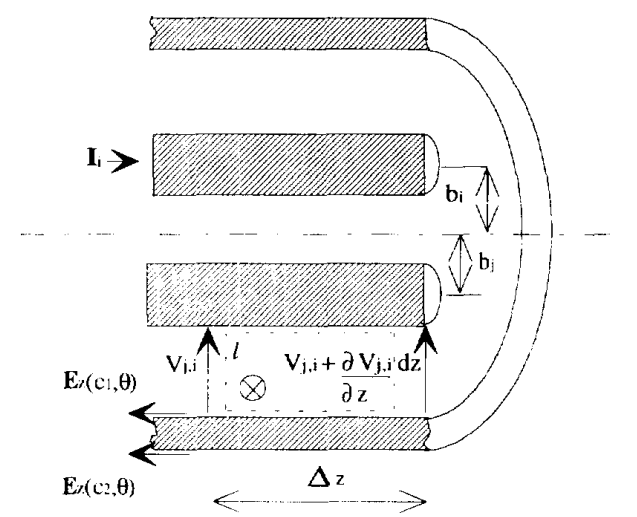

Fig. 3. Faraday's law application for mutual impedance determination.

\section{MATHEMATICAL RoutinES}

Asymptotic expansions are often used for Bessel function computations. However, in our applications, a wide range of frequencies is considered. Hence, the asymptotic forms can not be used succesfully in the whole interval. To avoid accumulation of errors due to small differences between large numbers, a recurrence relation is carried out : a backward recurrence for decreasing functions $\left(I_{n}(z)\right)$ and a forward one for increasing functions $\left(\operatorname{ker}_{n}(x), \operatorname{kei}_{n}(x)\right.$ with $\mathrm{z}=\mathrm{x} \quad \mathrm{j}$ $\exp (j \pi / 4)) . K_{n}(z)$ is calculated via $\operatorname{ker}_{n}(x)$ and $\operatorname{kei}_{n}(x)$. Due to space limitations, we describe briefly the calculation procedure of the function $I_{n}(z)$ [13].

-First, we determine the starting order of recurrence. It must not be small to avoid errors and, not too large to avoid supplementary time calculation [14].

-Secondly, a normalising factor built of a combination of Bessel functions is considered [13].

\section{RESULTS}

Many examples of cables are analyzed.

First, the case of a three core shielded cable system is considered. It is characterized by the following physical and geometrical parameters:

$$
\begin{aligned}
& \mu_{\mathrm{ri}}=1, \sigma_{\mathrm{i}}=3.33 \mathrm{E} 7 \mathrm{~S} / \mathrm{m}, \mathrm{a}_{1}=7 \mathrm{E}-3 \mathrm{~m}, \mathrm{a}_{2}=6 \mathrm{E}-3 \mathrm{~m}, . \\
& \mathrm{a}_{3}=6 \mathrm{E}-03 \mathrm{~m}, \theta_{1,2}=\theta_{2,3}=\theta_{3,1}=\pi / 3 . \\
& \mathrm{c}_{1}=26.8 \mathrm{E}-3 \mathrm{~m}, \mathrm{c}_{2}=28.8 \mathrm{E}-3 \mathrm{~m}, \mathrm{~b}_{1}=12 \mathrm{E}-3 \mathrm{~m}, \\
& \mathrm{~b}_{2}=13 \mathrm{E}-3 \mathrm{~m}, \mathrm{~b}_{3}=13 \mathrm{E}-3 \mathrm{~m}, \mu_{\mathrm{rg}}=1, \sigma_{\mathrm{g}}=4.76 \mathrm{E} 6 \mathrm{~S} / \mathrm{m} .
\end{aligned}
$$

One can notice according to Table I that the obtained results by the proposed model are in good agreement with those obtained by FEM.

TABLE I

SELF RESistanCE CALCULATION $\left\{\mathbf{R}_{1,1}\right.$ Tot $(\Omega / \mathrm{m})$.

\begin{tabular}{lccccccc} 
Frequency $\mathbf{F}(\mathrm{Hz})$ & 1 & IE2 & IE3 & 1E4 & 1E5 & $1 \mathrm{E} 6$ & 1E7 \\
\hline Present model & $8 \mathrm{E}-4$ & $8.3 \mathrm{E}-4$ & $1.1 \mathrm{E}-3$ & $2.1 \mathrm{E}-3$ & $6.2 \mathrm{E}-3$ & $2 \mathrm{E}-2$ & $6.3 \mathrm{E}-2$ \\
\hline FEM & $8 \mathrm{E}-4$ & $8.1 \mathrm{E}-4$ & $1.1 \mathrm{E}-3$ & $2 \mathrm{E}-3$ & $5.9 \mathrm{E}-3$ & $1.9 \mathrm{E}-2$ & $6.8 \mathrm{E}-2$ \\
\hline
\end{tabular}


The second validation concerns a four core shielded cable. The physical and geometrical parameters are expressed as follow:

$\mathrm{c}_{1}=2.17 \mathrm{E}-3 \mathrm{~m}, \mathrm{c}_{2}=2.37 \mathrm{E}-3 \mathrm{~m}, \mathrm{~b}_{1}=1.27 \mathrm{E}-3 \mathrm{~m}, \mathrm{~b}_{2}=1.27 \mathrm{E}-3 \mathrm{~m}$, $\mathrm{b}_{3}=1.27 \mathrm{E}-3 \mathrm{~m}, \mathrm{~b}_{4}=1.27 \mathrm{E}-3 \mathrm{~m}, \mathrm{a}_{1}=\mathrm{a}_{2}=\mathrm{a}_{3}=\mathrm{a}_{4}=0.45 \mathrm{E}-3 \mathrm{~m}$, $\mu_{\mathrm{rg}}=1, \sigma_{\mathrm{g}}=5.8 \mathrm{E} 07 \mathrm{~S} / \mathrm{m}, \mu_{\mathrm{ri}}=1, \sigma_{\mathrm{i}}=5.8 \mathrm{E} 7 \mathrm{~S} / \mathrm{m}$, $\theta_{12}=\theta_{23}=\theta_{34}=\theta_{41}=\pi / 2, \theta_{13}=\theta_{24}=\pi, \varepsilon_{\mathrm{ri}}=3$.

The inductance matrix $(\mathrm{L})$ of the cable calculated at $\mathrm{F}=10$ $\mathrm{MHz}$ by the present method is compared to those ( $\mathrm{L}^{\prime}$ ) obtained by measurement values of $\mathrm{C}_{\mathrm{ii}}$ and $\mathrm{C}_{\mathrm{ij}}$ [15]. The maximum relative obtained error is about $10 \%$.

$$
\mathrm{L}=\left[\begin{array}{cccc}
238 & 49.7 & 27.9 & 49.7 \\
49.7 & 238 & 49.7 & 27.9 \\
27.9 & 49.7 & 238 & 49.7 \\
49.7 & 27.9 & 49.7 & 238
\end{array}\right] \mathrm{nH} / \mathrm{m} . \mathrm{L}^{\prime}=\left[\begin{array}{cccc}
221.1 & 45.2 & 26.7 & 45.2 \\
45.2 & 221.1 & 45.2 & 26.7 \\
26.7 & 45.2 & 221.1 & 45.2 \\
45.2 & 26.7 & 45.2 & 221.1
\end{array}\right] \mathrm{nH} / \mathrm{m}
$$

The third example concerns a validation in the case of coaxial excentric shielded cable system. The physical and geometrical parameters are given in the following form.

$\mathrm{c}_{1}=5 \mathrm{E}-3 \mathrm{~m}, \mathrm{c}_{2}=7 \mathrm{E}-3 \mathrm{~m}, \mathrm{~b}_{1}=3 \mathrm{E}-3 \mathrm{~m}, \mathrm{a}_{1}=1 \mathrm{E}-3 \mathrm{~m}$,

$\left(\mu_{\mathrm{rg}}=1\right)$ et $\left(\sigma_{\mathrm{g}}=5.8 \mathrm{E} 07 \mathrm{~S} / \mathrm{m}\right)$

The shield inner surface resistance $\left(R_{s}\right)$ is calculated for different frequencies. The results obtained by the present model are first compared with those obtained by usual analytical models (with only skin effect consideration) and second with results obtained by FEM.

From Table II we point out that the results obtained with the skin effect model is only valid for low frequencies applications. The results obtained by the present model are in good agreement with those from FEM (the maximum relative error is $12 \%$ for $\mathrm{F}=10 \mathrm{MHz}$ ).

Finally, a two wire shielded cable system is investigated. The cable parameters are expressed as follow:

$\mu_{\mathrm{ri}}=1, \sigma_{\mathrm{i}}=5.8 \mathrm{E} 7 \mathrm{~S} / \mathrm{m}, \mathrm{a}_{\mathrm{i}}=1 \mathrm{E}-03 \mathrm{~m}, \mathrm{c}_{1}=5 \mathrm{E}-3 \mathrm{~m}, \mu_{\mathrm{rg}}=1$, $\mathrm{c}_{2}=7 \mathrm{E}-3 \mathrm{~m}, \mathrm{~b}_{1}=1.5 \mathrm{E}-3 \mathrm{~m}, \mathrm{~b}_{2}=1.5 \mathrm{E}-3 \mathrm{~m}, \sigma_{\mathrm{g}}=5.8 \mathrm{E} 07 \mathrm{~S} / \mathrm{m}$.

The frequency dependant mutual resistance $\left(\mathrm{R}_{2,1}\right.$ Tot $)$ and reactance $\left(\mathrm{X}_{2,1}\right.$ Tot $)$ are reported in Table III.

TABLE II

SHIELD INNER RESISTANCE CALCULATIONS, $\mathrm{R}_{\mathrm{S}}(\Omega / \mathrm{m})$.

\begin{tabular}{|c|c|c|c|c|c|c|c|}
\hline Frequency $F(\mathrm{~Hz})$ & 1 & IE2 & IE3 & $1 \mathrm{E} 4$ & $1 \mathrm{E5}$ & $1 \mathrm{E} 6$ & IE7 \\
\hline Skin effect alone & $2.3 \mathrm{E}-4$ & $2.3 \mathrm{E}-4$ & $2.5 \mathrm{E}-4$ & $7.8 \mathrm{E}-4$ & $2.6 \mathrm{E}-3$ & $8.2 \mathrm{E}-3$ & $2.6 \mathrm{E}-2$ \\
\hline Present model & $2.3 \mathrm{E}-4$ & $2.4 \mathrm{E}-4$ & 4. $1 \mathrm{E}-4$ & $1.5 \mathrm{E}-3$ & $5.3 \mathrm{E}-3$ & $1.8 \mathrm{E}-2$ & $5.6 \mathrm{E}-2$ \\
\hline FEM & $2.5 \mathrm{E}-4$ & $2.6 \mathrm{E}-4$ & 4.1E-4 & $1.5 \mathrm{E}-3$ & $6 \mathrm{E}-3$ & $2 \mathrm{E}-2$ & $6.4 \mathrm{E}-2$ \\
\hline
\end{tabular}

TABLE III

FREQUENCY DEPENDENT MUTUAL IMPEDANCE

\begin{tabular}{lccccccc} 
Frequency $\mathrm{F}(\mathrm{Hz})$ & 1 & $1 \mathrm{E} 03$ & $1 \mathrm{E} 04$ & $1 \mathrm{E} 05$ & $1 \mathrm{E} 06$ & $1 \mathrm{E} 07$ \\
\hline $\mathrm{R}_{2,1} \operatorname{Tot}(\Omega / \mathrm{m})$ & $2.3 \mathrm{E}-4$ & $2.3 \mathrm{E}-4$ & $1.2 \mathrm{E}-3$ & $5 \mathrm{E}-3$ & $1.7 \mathrm{E}-2$ & $5.4 \mathrm{E}-2$ \\
\hline $\mathrm{X}_{2,1} \operatorname{Tot}(\Omega / \mathrm{m})$ & $9.6 \mathrm{E}-7$ & $1 \mathrm{E}-3$ & $9.3 \mathrm{E}-3$ & $8.1 \mathrm{E}-2$ & 0.77 & 7.6 \\
\hline
\end{tabular}

It is important to note that, for high frequencies applications the internal inductances decay and become negligible. In this case, the main contribution to the overall inductance comes from the external inductances $\left(X_{2,1}\right.$ Tot $\approx j \omega$ $\mathrm{L}_{21}$ ).

\section{CONCLUSION}

A new and efficient model has been developed in this paper. Various investigations have been made for different cable configuration. The obtained results are in good agreement with validations in a frequency range about $[0 \mathrm{~Hz}$, $10 \mathrm{MHz}$. The proposed model is about ten time faster than the FEM.

\section{REFERENCES}

[1] M. Kane, S. Rathoin. Ph. Auriol, "Developpement de nouveaux modèles analytiques pour la détermination des impédances de câbles bifilaires blindés avec effets de proximités ", Actes du $7^{e ̀ m e}$ Colloque International CEM-94, Toulouse, pp. 349-354, 1994.

[2] M. Cao and P.P. Biringer- "BIE formulation for skin and proximity effect problems of parallel conductors", IEEE Trans. on Magnetics, vol. 26. no 5, pp. 2768-2770, 1990.

[3] P. Dokopoulos and D. Tampakis - "Eddy currents in a system of tubular conductors". IEEE Trans. on Magnetics, vol. 20, no 5, pp. 1971-1973, 1984

[4] A. Darcherif, A. Raizer, G. Meunier, J.F. Imhoff, and J. C. Sabonnadiere - "New techniques in FEM field calculation applied to power cable characteristics computation", IEEE Trans. on Magnetics, vol. 26, no. 5, pp. 2388-2390. 1990.

[5] K. Preis - " A contribution to eddy current calculations in plane and axisymmetric multiconductor systems ", IEEE Trans. on Magnetics, vol. 19, no. 6, pp. 2397-2400, 1983.

[6] A. Konrad. M.V.K. Chari and Z.J. Csendes - "New finite element techniques for skin effect problems", IEEE Trans. on Magnetics, vol. 18, no. 2, pp. $450-455,1982$.

[7] $\mathrm{M}$. Kane and $\mathrm{Ph}$. Auriol - "Analytical modelling of frequency parameters of lines ". IEE special proceedings of the 2nd International Conference on Computation in Electromagnetics, Nottingham, UK, pp. 239-242, 1994.

[8] A. Ametani, " A general formulation of impedance and admittance of cables ", IEEE Trans. on Power App. and Syst., vol. PAS-99, no. 3, pp. 902-910. May/June 1980.

[9] H. W. Dommel, "EMTP Theory book, " 1986.

[10] V. M. Malo' Machado, J. A. Brandao Faria, J. F. Borges da Silva, " Ground return effect on wave propagation parameters of overhead power cables ". IEEE Trans. on Power Delivery, vol. 5, no. 2, pp. 825832, April 1990.

[11] J. A. Tegopoulos and E. E. Kriezis, "Eddy currents in linear conducting media, " Elsevier. (1985)

[12] M. Kane, " Modèles analytiques originaux pour la détermination des paramètres linéiques des lignes et câbles multifilaires parcourus par des signaux large bande, " Rapport de Thèse, ECL, juillet 1994.

[13] S. A. Schelkunoff. " The electromagnetic theory of coaxial transmission line and cylindrical shields ", Bell Syst. Tech. J., vol. 13, pp. 532-579, 1934.

[14] M. Abramowitz and I. A. Stegun. "Handbook of Mathematical Functions ". Dover Publications, INC. New York. November 1970.

[15] T. Kasdepke. J. L. ter Haseborg, " A method for measuring the primary line parameters of multiconductor transmission lines ". International Symposium on EMC, Zurich, pp. 245-250, 1993. 